\title{
Pengaruh Pemupukan Berimbang Spesifik terhadap Pertumbuhan Tanaman Gaharu (Gyrinops versteegii) dan Perubahan Beberapa Sifat Kimia Tanah
}

\author{
A.A. NYOMAN SUPADMA*), I MADE DANA, DAN I MADE MEGA \\ Program Studi Agroekoteknologi Fakultas Pertanian Universitas Udayana Denpasar \\ ${ }^{*}$ E-mail: supadmaagung@ gmail.com
}

\begin{abstract}
Effect of Fertilizer (Organic + Inorganic + Dolomite) Combination to Improve of Growth Gaharu Plant (Gyrinops versteegii) and Characteristic of Soil Chemistry. This study aims to find combinations of fertilizer (organic + inorganic + dolomite) to promote the growth of gaharu plant and chemical properties of soil. This research was conducted in Tabanan Regency. The study was a randomized block design (RBD) with 7 treatments, each treatment was repeated three times to obtain 21 gaharu plants as a crop sample. The fertilizer formulations were tested as treatments as follows: $\mathrm{A}=$ without fertilizer (control), $\mathrm{B}=(50 \mathrm{~g}$ urea $+50 \mathrm{~kg} \mathrm{SP}-36+50 \mathrm{~kg} \mathrm{KCl}+10 \mathrm{~kg}$ compost $)+50 \mathrm{~g}$ Dolomite $)$ per tree, $\mathrm{C}=(100 \mathrm{~g}$ urea $+100 \mathrm{~g} \mathrm{SP}-36+100 \mathrm{~g} \mathrm{KCl}+7.5 \mathrm{~kg}$ compost $+75 \mathrm{~g}$ Dolomite $)$ per tree, $\mathrm{D}=(150 \mathrm{~g}$ urea $+150 \mathrm{~g} \mathrm{SP}-36+150 \mathrm{~g} \mathrm{KCl}+5 \mathrm{~kg}$ compost $+75 \mathrm{~g}$ Dolomite $)$ per tree, $\mathrm{E}=(200 \mathrm{~g}$ urea $+200 \mathrm{~g} \mathrm{SP}-36+200 \mathrm{~g} \mathrm{KCl}+2.5 \mathrm{~kg}$ of compost $+100 \mathrm{~g}$ Dolomite $)$ per tree, $\mathrm{F}=(200 \mathrm{~g}$ urea $+150 \mathrm{~g} \mathrm{SP}-36+150 \mathrm{~g} \mathrm{KCl}+7.5 \mathrm{~kg}$ of compost $+100 \mathrm{~g}$ Dolomite $)$ per tree, $\mathrm{G}=(200 \mathrm{~g}$ urea $+100 \mathrm{~g} \mathrm{SP}-36+100 \mathrm{~g} \mathrm{KCl}+7.5 \mathrm{~kg}$ of compost $+75 \mathrm{~g}$ Dolomite) per tree. Parameters measured were plant height, girth of plants, and chemical properties of the soil. Analysis of data using analysis of variance and Duncan test (0.05). The results showed that fertilization treatments significantly affected plant height, but not significant to girth of plant. The best fertilizer combinations was the treatment of $\mathrm{C}$, which were increase plant height $(26,35 \mathrm{~cm}), \mathrm{pH}(6,7)$, total $\mathrm{N}(0,28 \%)$ and other chemical properties of soil.
\end{abstract}

Keywords: fertilizer combinations, growth, gaharu plant, chemical properties of soil

\section{PENDAHULUAN}

Tanaman gaharu (Gyrinops versteegii) merupakan komoditi hasil hutan bukan kayu, mempunyai nilai ekonomis yang baik, merupakan komoditas ekspor, dan sumber pendapatan bagi masyarakat (Pasaribu et al., 2013). Menurut Santosa (2009) bahwa pemerintah Indonesia telah mencanangkan tanaman gaharu menjadi komoditi hasil hutan bukan kayu nasional yang terus 


\section{A.A. NYOMAN SUPADMA. et al. Pengaruh Pemupukan Berimbang Spesifik terhadap...}

dikembangkan dalam sekala yang lebih luas. Disebutkan pula bahwa tahun 2002 volume ekspor gaharu Indonesia hanya mencapai 30 ton, dengan nilai ekspor 600.000 dolar US. Kebutuhan gubal gaharu di luar negeri sangat tinggi karena manfaat gaharu cukup banyak yaitu untuk obat-obatan, parfum, kosmetik, dan keperluan ritual agama (Tarigan, 2004). Tetapi sampai dewasa ini produksi gaharu Indonesia relatif rendah dan terus mengalami penurunan dengan rata-rata produksi sekitar 45 ton per tahun.

Menurunnya produksi gaharu ini kemungkinan disebabkan masyarakat hanya mengandalkan pengambilan gaharu alam, tanpa adanya upaya pembudidayaannya. Agar kesinambungan produksi gaharu tetap terjaga, maka diperlukan adanya upayaupaya pembudidayaan tanaman gaharu yang benar, pemupukan yang tepat, sehingga dapat meningkatkan pertumbuhan dan menghasilkan gubal gaharu berkualitas baik.

Pengembangan budidaya gaharu di Indonesia sudah dilaksanakan di berbagai daerah seperti di Nusa Tenggara Barat, Kalimantan, Jawa, Papua, dan Bali. Budidaya gaharu di provinsi Bali telah dilaksanakan sejak tahun 2003 di beberapa kabupaten seperti kabupaten Tabanan, Jemberana, Bangli, dan Buleleng (Susila dan Mega, 2012). Budidaya gaharu yang dilaksanakan oleh petani di Bali belum intensif, karena kurangnya pengetahuan petani dan terbatasnya informasi teknologi budidaya serta teknologi pemupukan yang ada. Akibatnya adalah pertumbuhan tanaman belum maksimal dan pembentukan gubal gaharu rendah serta sangat lambat pada tanaman yang telah diinokulasi.
Untuk meningkatkan pertumbuhan tanaman garahu perlu dilakukan dengan menerapkan paket teknologi pemupukan berimbang spesifik yaitu pemupukan dengan menggunakan pupuk organik, pupuk alam, dan pupuk buatan (anorganik). Pupuk organik menyediakan hara yang lengkap dalam jumlah rendah, namun dapat memperbaiki sifat fisik dan biologi tanah. Sedangkan pupuk anorganik akan dapat menyediakan unsur hara lebih banyak dan lebih mudah tersedia bagi tanaman dibandingkan dengan pupuk organik, sedangkan pupuk alam (Dolomit) dapat menyediakan unsur hara tertentu lebih banyak seperti hara $\mathrm{Ca}$ dan $\mathrm{Mg}$ yang sangat esensial bagi tanaman (Rosmarkam \& Yuwono, 2002).

Untuk memperoleh kombinasi pupuk (organik + anorganik + Dolomit) yang tepat dan spesifik untuk tanaman gaharu, maka dilakukan penelitian: Pengaruh Pemupukan Berimbang Spesifik terhadap Pertumbuhan Tanaman Gaharu dan Perubahan Beberapa Sifat kimia Tanah yang dilakukan pada jenis tanah Inceptisol Marga, Tabanan.

\section{METODE PENELITIAN}

Penelitian ini merupakan percobaan lapangan pada kebun gaharu milik petani di Kecamatan Marga, Tabanan. Bahan-bahan yang diperlukan antara lain: kertas lebel, pupuk urea, SP-36, $\mathrm{KCl}$, pupuk alam Dolomit, dan bahan kimia. Alat-alat yang diperlukan untuk penelitian ini antara lain : cangkul, sabit, meteran, dan alat tulis.

Penelitian ini menggunakan rancangan acak kelompok (RAK) sederhana dengan jumlah perlakuan 7 kombinasi dosis pupuk, masing-masing diulang 3 kali sehingga 
diperlukan 21 pohon tanaman gaharu sebagai sampel.

Adapun perlakuan kombinasi pupuk yang dicoba sebagai berikut :

$\mathrm{A}=$ tanpa pupuk (kontrol), $\mathrm{B}=(50 \mathrm{~g}$ urea $+50 \mathrm{~kg} \mathrm{SP}-36+50 \mathrm{~kg} \mathrm{KCl}+10 \mathrm{~kg}$ kompos $+50 \mathrm{~g}$ Dolomit) per pohon, $\mathrm{C}=$ $(100 \mathrm{~g}$ urea $+100 \mathrm{~g} \mathrm{SP}-36+100 \mathrm{~g} \mathrm{KCl}+7,5$ $\mathrm{kg}$ kompos $+75 \mathrm{~g}$ Dolomit) per pohon, $\mathrm{D}=$ $(150 \mathrm{~g}$ urea $+150 \mathrm{~g} \mathrm{SP}-36+150 \mathrm{~g} \mathrm{KCl}+5$ $\mathrm{kg}$ kompos $+75 \mathrm{~g}$ Dolomit) per pohon, $\mathrm{E}=$ $(200 \mathrm{~g}$ urea $+200 \mathrm{~g} \mathrm{SP}-36+200 \mathrm{~g} \mathrm{KCl}+$ $2,5 \mathrm{~kg}$ kompos $+100 \mathrm{~g}$ Dolomit) per pohon, $\mathrm{F}=(200 \mathrm{~g}$ urea $+150 \mathrm{~g} \mathrm{SP}-36+150$ $\mathrm{g} \mathrm{KCl}+7,5 \mathrm{~kg}$ kompos $+100 \mathrm{~g}$ Dolomit) per pohon, $\mathrm{G}=(200 \mathrm{~g}$ urea $+100 \mathrm{~g} \mathrm{SP}-36+$ $100 \mathrm{~g} \mathrm{KCl}+7,5 \mathrm{~kg}$ kompos $+75 \mathrm{~g}$ Dolomit) per pohon. Sebelum tanaman gaharu diberikan perlakuan kombinasi pupuk, areal kebun yang telah ada pohon gaharu dibersihkan dari gulma. Selanjutnya tanaman dibagi menjadi 3 blok sebagai ulangan dan masing-masing blok ada 7 tanaman, kemudian masing-masing tanaman pada blok diberi lebel secara acak sesuai dengan kode perlakuan.

Pemberian dosis pupuk kompos, SP-36, $\mathrm{KCl}$, dan Dolomit dilaksanakan hari pertama sesuai perlakuan. Pupuk urea diberikan 2 kali masing-masing $50 \%$, yaitu 7 hari dan 28 hari setelah pemberian kompos. Pemberian pupuk dilaksanakan dengan cara membuat parit kecil sedalam $15 \mathrm{~cm}$ mengelilingi pangkal batang dengan radius $50 \mathrm{~cm}$. Kemudian pupuk diletakkan secara merata, diaduk sehingga tercampur merata dan ditutup kembali dengan tanah, disiram dengan air secukupnya.

Parameter yang diamati 3 bulan setelah pemupukan meliputi parameter pertumbuhan dan perubahan beberapa sifat kimia tanah disekeliling tanaman yaitu : tinggi tanaman (cm), lingkar batang $(\mathrm{cm})$, sifat kimia tanah 3 bulan setelah pemupukan : pH tanah (dengan $\mathrm{pH}$ meter), DHL (dengan Conductometer), KTK dan KB (pengekstrak NH4OAc. pH 7), C-organik (Wokly and Black), dan kadar N total (Kjeldhal), P-tersedia (Bray-1) (Spectrophotometer), dan K-tersedia (Bray1) (Flamephtometer), dianalisis di Lab. Tanah Fakultas Pertanian Universitas Udayana.

Untuk mengetahui pengaruh perlakuan terhadap parameter pertumbuhan yang diamati, maka dilakukan analisis sidik ragam sesuai dengan rancangan yang digunakan. Apabila perlakuan berpengaruh nyata maka dilanjutkan dengan uji beda (Duncans) pada taraf 5\%. Data perubahan sifat kimia tanah tidak dianalisis secara statistika, karena sampel tanah pada ulangan 1, 2 dan 3 digabung sesuai perlakuan, untuk mewakili perubahan sifat kimia tanah yang terjadi.

\section{HASIL DAN PEMBAHASAN}

Hasil analisis statistika menunjukkan bahwa perlakuan yang yang dicoba berpengaruh nyata terhadap parameter pertumbuhan yaitu pertambahan tinggi tanaman, namun berpengaruh tidak nyata terhadap parameter pertambahan lingkar batang tanaman seperti Tabel 1. 


\section{A.A. NYOMAN SUPADMA. et al. Pengaruh Pemupukan Berimbang Spesifik terhadap...}

Tabel1. Signifikansi perlakuan terhadap parameter tanaman gaharu

\begin{tabular}{|c|c|c|}
\hline No. & Jenis Parameter & Signifikansi \\
\hline 1. 7 & $\operatorname{aman}(\mathrm{cm})$ & $*$ \\
\hline 2. I & atang tanaman $(\mathrm{mm})$ & $\mathrm{ns}$ \\
\hline
\end{tabular}

Keterangan : $*$ = berbeda nyata $\quad$ ns = tidak berbeda nyata

Pertambahan tinggi tanaman gaharu tertinggi diperoleh pada perlakuan $\mathrm{C}$ yakni $24,33 \mathrm{~cm}$, berbeda nyata dengan control dengan pertambahan $11,55 \mathrm{~cm}$. Berbeda nyata pula dengan perlakuan $\mathrm{E}$ dan $\mathrm{F}$ dengan pertambahan tinggi berturut-turut $15,38 \mathrm{~cm}$, dan 11,35 cm seperti Tabel 2. Namun pengaruh perlakuan ternyata tidak berbeda nyata terhadap pertambahan lingkar batang, dan pertambahan lingkar batang terbesar juga diperoleh pada perlakuan C yakni 25,67 mm. Pengaruh perlakuan terhadap perubahan beberapa sifat kimia tanah cukup bervariasi, dan terjadi peningkatan sifat kimia tanah dibandingkan dengan kontrol seperti Tabel 2 dan Tabel 3. Perlakuan $\mathrm{C}$ memberikan pengaruh terbaik terhadap pertambahan tinggi dan lingkar batang tanaman, didukung oleh kondisi $\mathrm{pH}$ netral $(6,7)$, kadar C-organik tinggi $(3,46 \%)$, kadar N-total tanah sedang $(0,28 \%)$, kadar P-tersedia sangat tinggi (327,37 ppm), dan kadar K-tersedia sangat tinggi (438,12 ppm). Faktor sifat kimia tanah yang baik tersebut sangat berpengaruh terhadap pertumbuhan tanaman. Menurut Erfandi \& Kasno (2000) bahwa kadar hara N, P, K, KB dan KTK yang meningkat memberikan pengaruh yang baik terhadap pertumbuhan tanaman, sehingga menyebabkan meningkatnya pertambahan tinggi dan lingkar batang tanaman. Hasil penelitian Susila \& Mega (2012), pada tanaman gaharu diperoleh bahwa pemberian pupuk NPK sebanyak 0,30 $\mathrm{kg}$ per pohon, dan pupuk kompos bokhasi sebanyak 5,0 kg sampai 7,5 kg per pohon secara tunggal nyata dapat meningkatkan tinggi tanaman dan pertambahan lingkar batang tanaman gaharu. Setyorini et al. (2003) menyebutkan bahwa konsep pemupukan berimbang adalah bertujuan untuk menentukan takaran pupuk berdasarkan tingkat kesuburan tanah serta kebutuhan hara oleh tanaman. Perlakuan $\mathrm{C}$ memberikan kondisi keseimbangan hara yang terbaik bersumber dari pupuk organic, anorganik dan dolomit, sehingga dapat meningkatkan pertumbuhan tinggi tanaman yang baik, dan pertambahan lingkar batang yang terbesar. 
Tabel 2. Rerata pengaruh perlakuan terhadap peningkatan tinggi, lingkar batang tanaman gaharu

\begin{tabular}{llcc}
\hline No. Perlakuan & $\begin{array}{c}\text { Peningkatan } \\
\text { tinggi tanaman } \\
(\mathrm{cm})\end{array}$ & $\begin{array}{c}\text { Peningkatan } \\
\text { Lingkar batang } \\
(\mathrm{mm})\end{array}$ \\
\hline 1. & $\mathrm{A}$ & $11,55 \mathrm{~b}$ & $8,31 \mathrm{a}$ \\
2. & $\mathrm{~B}$ & $14,83 \mathrm{~b}$ & $9,73 \mathrm{a}$ \\
3. & $\mathrm{C}$ & $24,33 \mathrm{a}$ & $15,67 \mathrm{a}$ \\
4. & $\mathrm{D}$ & $18,50 \mathrm{ab}$ & $12,83 \mathrm{a}$ \\
5. & $\mathrm{E}$ & $15,38 \mathrm{~b}$ & $11,0 \mathrm{a}$ \\
6. & $\mathrm{~F}$ & $11,35 \mathrm{~b}$ & $13,33 \mathrm{a}$ \\
7. & $\mathrm{G}$ & $20,31 \mathrm{ab}$ & $15,00 \mathrm{a}$ \\
\hline
\end{tabular}

Keterangan : Angka-angka yang diikuti oleh huruf yang sama pada kolom yang sama berbedanyata pada Uji Duncans 5\%.

Dalam penelitian ini perlakuan $\mathrm{B}$ yakni perlakuan A dengan $\mathrm{pH}(6,3)$ agak memberikan kadar hara $\mathrm{N}, \mathrm{P}$, dan $\mathrm{K}$ yang masam, meningkat menjadi netral pada tertinggi yakni berturut-turut: $0,29 \%, 512,45$ perlakuan $\mathrm{C}(6,7)$ dan semua perlakuan yang ppm, 557,26 ppm, namun sedikit mengalami lain. Demikian pula bila dilihat kadar Cpenurunan pada perlakuan $\mathrm{C}$ yakni berturut- organik, KTK, dan KB tanah mengalami turut kadarnya : 0,28 \%, 327,37 ppm, dan peningkatan pada semua perlakuan 438,12 ppm. Pengaruh perlakuan terhadap dibandingkan dengan kontrol seperti pada pH tanah menunjukkan terjadi peningkatan Tabel 3 dan Tabel 4.

Tabel 3. Pengaruh perlakuan terhadap perubahan beberapa sifat kimia tanah ( $\mathrm{pH}, \mathrm{C}$-organik, N-total, P-tersedia, K-tersedia) pada akhir penelitian.

\begin{tabular}{lccccrc}
\hline No. & Perlakuan & $\mathrm{pH}$ & $\begin{array}{c}\text { C-org } \\
(\%)\end{array}$ & $\begin{array}{l}\text { N-tot } \\
(\%)\end{array}$ & $\begin{array}{r}\text { P-ters } \\
(\mathrm{ppm})\end{array}$ & $\begin{array}{l}\text { K-ters } \\
(\mathrm{ppm})\end{array}$ \\
\hline 1. & $\mathrm{A}$ & 6,3 & 3,06 & 0,19 & 73,12 & 154,34 \\
2. & $\mathrm{B}$ & 6,5 & 4,32 & 0,29 & 512,45 & 557,26 \\
3. & $\mathrm{C}$ & 6,7 & 3,46 & 0,28 & 327,37 & 438,12 \\
4. & $\mathrm{D}$ & 6,8 & 4,51 & 0,22 & 235,86 & 312,57 \\
5. & $\mathrm{E}$ & 6,7 & 4,56 & 0,21 & 247,49 & 328,88 \\
6. & $\mathrm{F}$ & 6,7 & 4,67 & 0,23 & 337,28 & 379,56 \\
7. & G & 6,5 & 4,75 & 0,24 & 408,19 & 512,53 \\
8. Tanah awal & 6,1 & 3,04 & 0,19 & 69,45 & 138,77 \\
& & & & & & \\
\hline
\end{tabular}




\section{A.A. NYOMAN SUPADMA. et al. Pengaruh Pemupukan Berimbang Spesifik terhadap...}

Tabel 4. Pengaruh perlakuan terhadap perubahan beberapa sifat kimia tanah (DHL, KTK, KB) pada akhir penelitian.

\begin{tabular}{lcccc}
\hline No. & Perlakuan & $\begin{array}{c}\text { DHL } \\
(\mathrm{mmhos})\end{array}$ & $\begin{array}{c}\text { KTK } \\
(\mathrm{me} / 100 \mathrm{~g})\end{array}$ & $\begin{array}{c}\mathrm{KB} \\
(\%)\end{array}$ \\
\hline 1 & $\mathrm{~A}$ & 0,28 & 36,03 & 73,06 \\
2 & $\mathrm{~B}$ & 0,33 & 44,16 & 90,31 \\
3 & $\mathrm{C}$ & 0,46 & 44,14 & 86,96 \\
4 & $\mathrm{D}$ & 0,60 & 38,55 & 90,16 \\
5 & $\mathrm{E}$ & 0,63 & 39,84 & 90,14 \\
6 & $\mathrm{~F}$ & 0,70 & 40,63 & 88,12 \\
7 & $\mathrm{G}$ & 0,60 & 42,85 & 80,93 \\
8 & Tanah awal & 0,17 & 35,45 & 75,39 \\
\hline
\end{tabular}

Meningkatnya pertambahan lingkar batang tanaman gaharu akan memberikan kondisi yang baik bagi jamur Fusarium solani dan Rhisopus sp. sebagai inokulan dalam menginfeksi jaringan batang gaharu, sehingga kemungkinan akan terbentuk gubal gaharu yang meningkat pula. Dalam penelitian ini belum dilakukan pengamatan pembentukan gubal, namun perlakuan $\mathrm{C}$ menghasilkan pertambahan lingkar batang yang yang terbesar, sehingga kemungkinan nantinya dapat membentuk gubal yang lebih banyak. Pada perlakuan $\mathrm{C}$ yakni mengandung $\mathrm{N}$-total sedang, P-tersedia sangat tinggi, dan K-tersedia sangat tinggi, sehingga sangat membantu pertumbuhan sel jaringan tanaman gaharu (Rosmarkam et al.,2002). Selain itu penambahan pupuk Dolomit yang mengandung hara $\mathrm{Mg}$ dan $\mathrm{Ca}$, kemungkinan dapat meningkatkan kadar $\mathrm{Mg}$ dan $\mathrm{Ca}$ tersedia di dalam tanah, sehingga kemungkinan serapan hara $\mathrm{Mg}$ meningkat untuk membentuk klorofil yang berperan dalam proses fotosintesis, dan serapan hara $\mathrm{Ca}$ untuk pembentukan dinding sel jaringan tanaman. Kondisi tersebut sangat mendukung berlangsungnya proses fotosintesa dengan baik untuk meningkatkan pertumbuhan tanaman antara lain tinggi tanaman, serta penambahan lingkar batang gaharu.

\section{SIMPULAN}

Berdasarkan hasil penelitian ini maka dapat diambil kesimpulan sebagai berikut : Perlakuan pemupukan berimbang spesifik (organic+anorganik+dolomite) yang dicoba berpengaruh nyata terhadap pertambahan tinggi tanaman, namun tidak berpengaruh nyata terhadap pertambahan lingkar batang tanaman gaharu. Pertambahan tinggi tanaman dan lingkar batang terbaik diperoleh pada perlakuan C yakni berturut-turut $24,33 \mathrm{~cm}$, dan $15,67 \mathrm{~cm}$.

Perubahan sifat kimia tanah pada perlakuan $\mathrm{C}$ sebagai berikut : kadar N-total (sedang), kadar P-tersedia (sangat tinggi), Ktersedia (sangat tinggi), $\mathrm{pH}$ (netral), Corganik tanah (tinggi), dan Daya Hantar Listrik (sangat rendah), KTK (tinggi) dan KB (sangat tinggi). 


\section{UCAPAN TERIMA KASIH}

Terimakasih yang sebesar-besarnya diucapkan kepada Rektor Universitas Udayana, Ketua LPPM dan Dekan Fakultas Pertanian Universitas Udayana atas bantuan dana dan ijin yang diberikan, sehingga penelitian ini dapat berlangsung dengan lancar.

\section{DAFTAR PUSTAKA}

Erfandi, D.,A. Kasno, 2000. Efektivitas Penggunaan Pupuk anorganik dan organik untuk meningkatkan Produktivitas Tanah pada lahan kering masam. Prosiding HITI. VII. Bandung.

Mega, I.M., Suanda,D.W., D.N., Kasniari, W. Suena, \& M.O. Parwata.,2012. Formulasi Inokulan Jamur Pembentuk Gubal Gaharu pada Tanaman Ketimunan (Gyrinops versteegii). J. Agrotrop 2 (2) : 139144.

Pasaribu, G., Waluyo, T.K. \& Pari, G., 2013. Analisis Komponen Kimia Beberapa Kualitas Gaharu dengan Kromatografi Gas Spektrometri Massa. J. Penelitian Hasil Hutan 31 (3) : 181-185.

Rosmarkam, A. \& Yuwono, N.W., 2002. Ilmu Kesuburan Tanah. Penerbit Kanisius. Yogyakarta.

Santosa, H. , 2009. Kolam Smpaikan danservasi dan Pemanfaatan Gaharu. Disampaikan dalam Seminar Nasional I Gaharu. Bogor.

Setyorini,D., J.S. Adiningsih \& S. Rohayati, 2003. Uji Tanah Sebagai Dasar Penyusunan Rekomendasi Pemupukan. Balai Penelitian Tanah. Bogor.
Susila, D. \& I.M. Mega, 2012. Aplikasi Pemupukan Berimbang untuk Peningkatan Laju Pertumbuhan Tanaman Gaharu (Gyrinops verstegii) di Kabupaten Tabanan. J.Agrotrop 2 (1) : 10-16.

Tarigan , K., 2004. Profil Pengusahaan (Budidaya) Gaharu. Departemen Kehutanan. Pusat Bina Penyuluhan Kehutanan. Jakarta. 